\title{
OS DOIS MODOS FUNDAMENTAIS DE RELAÇÃO DO HOMEM COM O DADO TÉCNICO'
}

\author{
Américo Grisotto ${ }^{2}$ \\ Marcos Alexandre Gomes Nalli \\ Patrícia Maria Weffort
}

\section{$[85]^{3}$ I. Maioridade e menoridade social das técnicas}

Gostaríamos de mostrar que o objeto técnico pode estar vinculado ao homem de duas maneiras opostas: segundo um estatuto de maioridade ou um estatuto de menoridade. $\mathrm{O}$ estatuto de menoridade é aquele de acordo com o qual o objeto técnico é, antes de tudo, objeto de uso, necessário à vida cotidiana, fazendo parte do ambiente em que o indivíduo humano cresce e se forma. $\mathrm{O}$ encontro entre o objeto técnico e o homem efetua-se essencialmente, neste caso, durante a infância. O saber técnico é implícito, não refletido, costumeiro. O estatuto de maioridade corresponde, pelo contrário, a uma tomada de consciência e a uma operação reflexiva do adulto livre, que tem à sua disposição os meios de conhecimento racional elaborados pelas ciências: o conhecimento do aprendiz se opõe desta forma ao conhecimento do engenheiro. $\mathrm{O}$ aprendiz que se tornou artesão adulto e o engenheiro inserido na rede de relações sociais, conservam e irradiam em torno deles uma visão do objeto técnico que corresponde, no primeiro caso, ao estatuto de menoridade e, no segundo, ao estatuto de maioridade; são duas fontes muito diferentes de representação e de julgamento relativas ao objeto técnico. Contudo, o artesão e o engenheiro não vivem apenas por eles mesmos; testemunhas e agentes da relação entre a sociedade humana e seu conjunto e o mundo dos objetos técnicos e seu conjunto, têm um valor exemplar: através deles, o objeto técnico incorpora-se à cultura. Até hoje, esses dois modos de incorporação não podiam chegar a resultados concordantes, embora existam como duas [86] linguagens e dois tipos de pensamento que emergem das técnicas e que não são coerentes um com o outro. Esta falta de coerência é em parte responsável pelas contradições contidas na cultura atual, na medida em que ela julga e representa para si mesma o objeto técnico em relação ao homem.

1 Primeiro capítulo da segunda parte da obra de Gilbert Simondon Du mode d'existence des objets tecniques. Paris: Editions Aubier, 1958: Les deux modes fondamentaux de relation de l'homme au donné technique.

2 Tradução de Patrícia Maria Weffort, Mestra em Filosofia (PROF-FILO) pela Universidade Federal do Paraná (UFPR), patyweffort@hotmail.com e Américo Grisotto, Professor Adjunto do Departamento de Filosofia da Universidade Estadual de Londrina (UEL), grisotto@uel.br, com a revisão de Marcos Alexandre Gomes Nalli, Professor Associado do Departamento de Filosofia da Universidade Estadual de Londrina (UEL), nalli@uel.br.

3 Paginação do texto em francês: SIMONDON, Gilbert. Du mode d'existence des objets tecniques. Paris: Editions Aubier, 1958. 
Esse conflito entre o aspecto de maioridade e o aspecto de menoridade nada mais é que um caso particular da inadequação que sempre existiu entre o homem individual ou social e a realidade técnica. $\mathrm{Na}$ antiguidade, uma grande parte das operações técnicas eram rejeitadas, colocadas para fora do domínio do pensamento: eram operações que correspondiam às ocupações servis. Da mesma maneira que o escravo era colocado para fora da cidade, do mesmo modo as ocupações servis, os objetos técnicos que lhes correspondiam eram varridos do universo do discurso, do pensamento reflexivo, da cultura. Apenas os Sofistas, e até certo ponto Sócrates, fizeram o esforço por fazer entrar no domínio do pensamento nobre as operações técnicas praticadas por escravos ou pelos libertos. O estatuto de maioridade só estava estabelecido para algumas operações como a agricultura, a caça, a guerra, a arte da navegação. As técnicas que usaram ferramentas eram mantidas fora do domínio da cultura (Cícero extrai quase todas as suas metáforas das artes nobres, particularmente da agricultura e da navegação; raramente invoca as artes mecânicas).

Voltando ainda mais no passado, encontraríamos que esta ou aquela civilização também realizava uma escolha entre técnicas nobres e aquelas que não o eram; a história do povo hebreu concede um verdadeiro privilégio para as técnicas pastorais e considera a terra maldita. O Eterno aceita as ofertas de Abel e não as de Caim: o pastor é superior ao agricultor. A Bíblia contém uma infinidade de estruturas de pensamento de paradigmas extraídos de maneira a fazer prosperar os rebanhos. Os Evangelhos, ao contrário, introduzem formas de pensar extraídas da experiência da agricultura. Talvez poderíamos encontrar, nas origens das mitologias e religiões, um certo viés tecnológico, consagrando como nobre uma técnica e negando o direito a outras, mesmo quando elas são efetivamente utilizadas; esta escolha inicial entre uma técnica majoritária e uma técnica minoritária, entre uma técnica valorizada e uma técnica desvalorizada, oferece à cultura, que incorpora os esquemas técnicos assim descobertos, um aspecto de parcialidade e de não-universalidade. Nossa busca não se destina a descobrir, em cada caso particular, as razões e [87] as modalidades desta escolha entre as técnicas fundamentais, mas apenas mostrar que o pensamento humano deve instituir uma relação igual, sem privilégio, entre as técnicas e o homem. Esta tarefa está por ser cumprida, porque os fenômenos de domínio técnico, que fazem com que, em cada época, exista uma parte do mundo técnico reconhecido pela cultura, enquanto em outras são rejeitadas, mantêm uma relação inadequada entre a realidade humana e a realidade técnica.

\begin{tabular}{|l|l|l|l|l|}
\hline Qevista Dialectus & Ano 9 & n. 19 & Agosto - Dezembro 2020 & p. 322 - 347 \\
\hline
\end{tabular}


A supressão da escravidão na Europa Ocidental permitiu às antigas técnicas servis virem à luz e se manifestarem em um pensamento claro: o Renascimento consagrou as técnicas artesanais lhes oferecendo a luz da racionalidade. A mecânica racional inseriu as máquinas no domínio do pensamento matemático: Descartes calculou as transformações do movimento nas máquinas simples utilizadas por escravos da Antiguidade. Esse esforço de racionalização, que significa integração à cultura, continuou até o final do século XVIII. Apesar disto, a unidade das técnicas não foi preservada; operou-se uma verdadeira reversão que rechaçou as antigas técnicas nobres (as da agricultura e as de criação de animais), deixando-as no domínio do irracional, do não-cultural; perdeu-se a relação com o mundo natural e o objeto técnico tornouse um objeto artificial que distancia o homem do mundo. Dificilmente podemos entrever em nossos dias um meio de aproximação entre um pensamento inspirado pelas técnicas relativas aos seres vivos e o pensamento artificialista, construtor de autômatos. As técnicas mecânicas não podem se tornar verdadeiramente majoritárias, a não ser que, ao invés de continuarem a ser técnicas artesanais, se tornem técnicas pensadas pelo engenheiro; em nível artesanal, a relação concreta entre o mundo e o objeto técnico ainda existe; mas o objeto pensado pelo engenheiro é um objeto técnico abstrato, não ligado ao mundo natural. Para que a cultura possa incorporar os objetos técnicos, seria necessário descobrir um caminho intermediário entre o estatuto de maioridade e o estatuto de menoridade dos objetos técnicos. A disjunção entre a cultura e a técnica tem sua condição na disjunção que existe no interior do próprio mundo das técnicas. Para descobrir uma relação adequada entre o homem e o objeto técnico, é necessário descobrir uma unidade do mundo técnico, através de uma representação que incorporasse, simultaneamente, aquela do artesão e a do engenheiro. A representação do artesão está imersa no concreto, engajada na manipulação material e a existência sensível; está [88] dominada por seu objeto; a do engenheiro é dominadora; faz do objeto um feixe de relações mensuradas, um produto, um conjunto de características.

Assim, a primeira condição de incorporação dos objetos técnicos à cultura seria a de que o homem não fosse inferior nem superior aos objetos técnicos, que possa abordá-los e aprender a conhecê-los, mantendo com eles uma relação de igualdade, de reciprocidade de trocas: de certa maneira, uma relação social.

A compatibilidade ou incompatibilidade entre os diferentes modos tecnológicos merece ser submetida a uma análise condicional. Talvez seja possível descobrir as condições

\begin{tabular}{|l|l|l|l|l|}
\hline Qevista Dialectus & Ano 9 & n. 19 & Agosto - Dezembro 2020 & p. 322 - 347 \\
\hline
\end{tabular}


de compatibilidade entre uma tecnologia como a dos romanos e uma outra, como as que são elaboradas pelas sociedades civilizadas em nossos dias: talvez até seja possível descobrir uma incompatibilidade real, embora não muito aparente, entre as condições tecnológicas do século XIX e as de meados do século XX. Certos mitos nascidos do encontro abusivo de dois paradigmatismos tecnológicos incompatíveis, poderão, então, ser levados às suas condições iniciais e analisados.

\section{Técnica aprendida pela criança e técnica pensada pelo adulto}

Não se pode estudar o estatuto do objeto técnico em uma civilização sem envolver a diferença entre as relações desse objeto com o adulto e a criança; mesmo que a vida nas sociedades modernas nos ofereceu o hábito de pensar que há uma continuidade entre a vida da criança e a do adulto, a história da educação técnica nos mostra rapidamente que a distinção existiu, e que as características da aquisição de conhecimentos técnicos não são as mesmas, dependendo se essa aquisição ocorre em uma criança ou em um adulto; não temos a mínima intenção de estabelecer uma regra normativa, apenas queremos mostrar que os caracteres do ensino das técnicas variaram muito ao longo do tempo, e que eles modificaram não só devido ao estado das técnicas, ou da estrutura das sociedades, mas também em razão da idade dos sujeitos que estavam submetidos à aprendizagem; poderíamos descobrir aqui uma relação circular de causalidade entre o estado das técnicas e a idade de aquisição dos conhecimentos que constituem a bagagem do [89] técnico; se uma técnica, muito pouco racionalizada, exige o início extremamente precoce de aprendizagem, o sujeito, mesmo tornando-se adulto, manterá uma irracionalidade de base em seus conhecimentos técnicos; ele os possuirá em virtude de uma impregnação habitual muito profunda porque adquirida muito cedo; por isso mesmo, o conhecimento desse técnico não consistirá em estruturas claramente representadas, mas em habilidades possuídas quase que por instinto, e confiadas àquela segunda natureza que é o hábito. Sua ciência estará no nível das representações sensoriais e qualitativas, muito próximas das características concretas da matéria; este homem estará dotado de um poder de intuição e de conivência com o mundo que lhe dará uma habilidade muito notável manifesta apenas na obra, e não na consciência ou no discurso; o artesão será como um mago, e seu conhecimento será mais operacional que intelectual; será uma capacidade mais que um saber; por sua própria

\begin{tabular}{|c|c|c|c|c|}
\hline Rovista Dialectus & Ano 9 & ก. 19 & Agosto - Dezembro 2020 & p. $322-347$ \\
\hline
\end{tabular}


natureza, será secreto para os outros, porque será secreto para ele mesmo, para a sua própria consciência.

Ainda hoje, essa existência de um subconsciente técnico não formulado em termos claros pela atividade reflexiva encontra-se entre os camponeses ou pastores, capazes de apreender diretamente o valor das sementes, a exposição de um terreno, o melhor lugar para plantar uma árvore ou para estabelecer um parque de modo que ele seja protegido e bem localizado. Esses homens são experts no sentido etimológico do termo: eles fazem parte da natureza viva da coisa que eles conhecem, e seu saber é um saber da participação direta e profunda que necessita de uma simbiose original, que comporta uma espécie de fraternidade com um aspecto do mundo, valorizado e qualificado.

O homem conduz-se aqui como o animal que sente à distância a água ou sal, que sabe escolher o local do ninho de modo imediato e sem raciocínios prévios. Tal participação é instintiva por natureza e não se encontra senão quando a vida de sucessivas gerações produziu uma adaptação do ritmo de vida, das condições da percepção e das estruturas mentais essenciais a um gênero de atividade direcionada a uma natureza estável. Hoffmann, num conto notável intitulado A Mina, descreve um poder semelhante de intuição no verdadeiro mineiro; ele sente o perigo e sabe como descobrir o mineral nos filões mais escondidos; vive em uma espécie de conaturalidade com a natureza subterrânea, e essa conaturalidade é tão profunda que exclui qualquer outro sentimento ou vínculo; o verdadeiro mineiro é um homem subterrâneo [90]; aquele que desce à mina sem amá-la, como aquele marinheiro errante que se engaja corajosamente para trabalhar na mina, porque apaixonado por uma jovem, ele não descobrirá essa conaturalidade essencial; será uma vítima da mina na mesma manhã do seu casamento. Não há aqui nenhum nuance moral; o jovem marinheiro estará cheio de mérito e virtude. Mas é marinheiro e não mineiro; ele não tem a intuição da mina. $\mathrm{O}$ fantasma do velho mineiro o advertiu do perigo que ele corre, pois a mina não aceitou o intruso, aquele que vem de fora, de outro trabalho, de outra vida, e que não é dotado do poder de participação. A natureza humana, no camponês, pastor, mineiro, marinheiro, duplica-se assim em uma segunda natureza que é como um pacto ancestral com um elemento ou uma região. É difícil dizer se esse sentimento de participação é adquirido nos primeiros anos ou se está envolvido em um patrimônio hereditário, mas parece certo que uma semelhante formação técnica, consiste em intuições e em esquemas operatórios puramente concretos, muito dificilmente formuláveis e transmissíveis por um

\begin{tabular}{|l|l|l|l|l|}
\hline Qevista Dialectus & Ano 9 & n. 19 & Agosto - Dezembro 2020 & p. 322 - 347 \\
\hline
\end{tabular}


simbolismo qualquer, oral ou figurativo, pertencente à infância. Por essa mesma razão, muito dificilmente é evolutiva, e quase não pode ser reformada na idade adulta: ela não é, com efeito, de natureza conceitual ou científica, e não pode ser modificada por um simbolismo intelectual, oral ou escrito.

Esta formação técnica é rígida. Seria completamente abusivo considerar esta formação técnica como necessariamente inferior a outra que use símbolos intelectuais; a quantidade de informação desta formação de tipo instintivo pode ser tão grande quanto a que contém um conhecimento claramente explicável em símbolos, com gráficos, esquemas ou fórmulas; é muito fácil opor a rotina à ciência, que seria simultaneamente o progresso; o que é relativo ao primitivo não poderia ser confundido com a tolice, nem mesmo a conceptualização com a ciência. Mas é importante notar que esse conhecimento técnico é efetivamente rígido, já que o homem não pode tornar-se novamente criança a fim de adquirir novas intuições como base. Esta forma de técnica tem além disso uma segunda característica: é iniciatória e exclusiva; de fato, ao crescer dentro de uma comunidade já totalmente impregnada de esquemas de um trabalho determinado, a criança adquire suas intuições de base; aquele que vem de fora muito provavelmente será privado desta participação inicial que exige a existência de condições vitais, porque as condições são educativas neste primeiro sentido. Seria sem dúvida abusivo atribuir o [91] fechamento das técnicas antigas para o fechamento da vida comunitária das sociedades: de fato, essas sociedades sabiam se abrir, conforme mostra a migração temporária ou sazonal dos camponeses de Auvergne à Paris, até o fim do século XIX; é a técnica em si mesma que corresponde, neste caso, a um regime fechado de vida, porque a formação técnica só é valiosa para a sociedade que a formou e é a única coisa válida para essa sociedade. Parece que historiadores têm sido inclinados a considerar, de maneira muito abstrata, os ritos de iniciação dos antigos ofícios, tratando-os sob um ponto de vista puramente sociológico; deve-se notar que as provas correspondem, por parte da criança, a um regime de aquisição do conhecimento técnico; a prova não é somente um rito social, mas também o ato pelo qual o jovem se torna adulto dominando o mundo, medindo-se com ele em uma circunstância crítica e triunfando sobre ele. Há uma certa carga de magia na prova, que é um ato pelo qual a criança se torna um homem usando pela primeira vez de todas as suas forças levando-as ao seu limite extremo. Neste corpo a corpo perigoso com o mundo e a matéria, arrisca a eficácia de sua ação de homem, se enfraquece ou se revela inferior. Se a natureza hostil não se deixa derrotar, o homem não

\begin{tabular}{|l|l|l|l|l|}
\hline Q & Ano & n. 19 & Agosto - Dezembro 2020 & p. $322-347$ \\
\hline
\end{tabular}


pode se tornar um adulto completo, porque um fosso foi aberto entre ele e a natureza; a prova é um feitiço do ser técnico por toda a vida; é uma operação que cria a obediência da matéria a um homem que se tornou seu mestre porque ele conseguiu domesticá-la, como um animal que se torna dócil desde o dia em que foi conduzido pela primeira vez. Se o primeiro gesto falha, o animal se revolta e permanece grosseiro; ele jamais aceitará esse mestre que, por sua vez, não terá a segurança garantida, porque o contato imediato está quebrado. Na prova, manifesta-se a lei do tudo ou nada; o homem e o mundo aí se transformam; uma união assimétrica aí se institui; não devemos dizer que a prova manifesta a coragem ou a habilidade como puro exame; ela cria essas qualidades, pois a coragem é feita de uma ligação imediata e segura com o mundo, que afasta toda incerteza e toda dúvida; a coragem não é um medo superado, mas um medo sempre adiado pela presença da intuição que faz o mundo estar junto daquele que age; o homem hábil é aquele que o mundo aceita, que a matéria ama e ao qual ela obedece com a fiel docilidade do animal que reconheceu um mestre. A habilidade é uma das formas da potência, e a potência supõe um feitiço [92] tornando possível uma troca de forças, ou melhor, um modo de participação mais primitivo e mais natural que o do feitiço, já muito elaborado e parcialmente abstrato. Nesse sentido, a habilidade não é o exercício de um despotismo violento, mas o de uma força conforme ao ser que ela conduz. Na verdadeira potência do homem hábil há uma relação de causalidade recorrente. O verdadeiro técnico ama a matéria sobre a qual age; ele está do seu lado; ele é um iniciado, mas respeita aquilo no qual foi iniciado; depois de a ter dominado, ele forma um par com esta matéria e não a livra do profano, senão com reversa, porque guarda o sentido do sagrado. O artesão, o camponês, ainda experimentam em nossos dias uma repugnância no sentido de livrar do comércio certas obras ou produtos que expressam sua atividade técnica mais refinada e mais perfeita: esta proibição da comercialização, da divulgação, manifesta-se por exemplo, no caso dos exemplares fora da circulação comercial que um impressor, um editor e um autor podem fazer com relação a um livro. Manifesta-se também no caso do camponês dos Pirineus que oferece à sua visita, em sua casa, um determinado alimento que não permite que seja comprado, nem levado dali.

O caráter secreto e involutivo de semelhante técnica não é senão um produto de condições sociais; ele produz a estrutura dos grupos tanto quanto esta estrutura do grupo o condiciona. E pode ser que toda técnica deve, em certa medida, carregar consigo um certo coeficiente de intuição e instinto, necessários para o estabelecimento de uma comunicação

\begin{tabular}{|l|l|l|l|l|}
\hline Qevista Dialectus & Ano 9 & n. 19 & Agosto - Dezembro 2020 & p. 322 - 347 \\
\hline
\end{tabular}


conveniente entre o homem e o ser técnico. Mas de par com esse primeiro aspecto da formação técnica, há um segundo que é o inverso do precedente, e que se dirige essencialmente ao homem adulto. Da mesma forma que o precedente, há uma ação dinâmica sobre o homem individual e sobre o grupo, conduzindo-o a possuir uma mentalidade adulta.

Este segundo tipo de conhecimento técnico, é o conhecimento racional, teórico, científico e universal. O melhor exemplo nos é oferecido pela Enciclopédia de Diderot e d'Alembert. Se a Enciclopédia apareceu como uma obra poderosa e perigosa, não foi por causa dos ataques, velados ou diretos, contra certos abusos ou privilégios, nem por causa do caráter "filosófico" de certos artigos; existiam vários livros e panfletos mais violentos do que a Enciclopédia. Mas a Enciclopédia era temida porque movida por uma força enorme, a do enciclopedismo técnico, força que a havia conciliado a protetores influentes e esclarecidos; esta força existia por ela mesma, porque [93] respondia, bem mais do que às reformas políticas ou financeiras, a uma necessidade da época; esta força que era positiva e criativa, realizava também um notável agrupamento de investigadores, de redatores, de correspondentes, oferecendo uma fé a esta equipe composta por homens que colaboraram, independentemente de estarem ligados entre eles por comunidades sociais ou religiosas; uma grande obra estava por se realizar. A grandeza da Enciclopédia, sua novidade, reside no caráter de funcionamento maior, dessas gravuras de esquemas e de modelos de máquinas, que são uma homenagem aos ofícios e ao conhecimento racional das operações técnicas. Contudo, essas ilustrações não cumprem um papel de pura documentação desinteressada para um público ansioso para satisfazer sua curiosidade; a informação aí presente está bastante completa para constituir uma documentação de utilização prática, de tal maneira que todo homem que disponha da obra seja capaz de construir a máquina descrita, ou fazê-la avançar pela invenção, pelo estado alcançado pela técnica neste domínio, e iniciar a sua busca no ponto onde terminaram os homens que o precederam.

O método e a estrutura deste novo ensino são inversos daqueles do precedente: ele é racional e duplamente universal; é por este motivo que ele é adulto. É racional porque emprega a medida, o cálculo, os procedimentos de figuração geométrica e análise descritiva; racional também porque se vale de explicações objetivas e invoca os resultados da experiência, com o cuidado da exposição precisa das condições, tratando como hipótese o que é conjectural e como fato estabelecido o que deve ser considerado como tal; não apenas uma explicação científica se

\begin{tabular}{|l|l|l|l|l|}
\hline Qevista Dialectus & Ano 9 & n. 19 & Agosto - Dezembro 2020 & p. 322 - 347 \\
\hline
\end{tabular}


faz necessária, mas ela é necessária se acompanhada de um gosto nítido pelo espírito científico. Por outro lado, esse ensino é duplamente universal, às vezes pelo público ao qual ele é endereçado e pela informação que oferece. Por certo, os conhecimentos que são ensinados são de um alto nível, mas apesar disso são destinados a todos; somente o preço do trabalho limita as possíveis compras. Esses conhecimentos estão dados no espírito com a mais alta universalidade possível, de acordo com um esquema circular que jamais supõem uma operação técnica fechada nela mesma no segredo da sua especialidade, mas ligada a outras, empregando tipos de aparelhos análogos e que se baseiam em um pequeno número de princípios. Pela primeira vez, vemos se constituir um universo técnico, um cosmos onde tudo está ligado a tudo em vez de ser guardado zelosamente por uma corporação. Esta universalidade consistente e objetiva, que supõe uma ressonância interna deste [94] mundo técnico, exige que a obra esteja aberta a todos e constitua uma universalidade material e intelectual, um bloco de conhecimentos técnicos disponíveis e abertos. Este ensino supõe um sujeito adulto, capaz de dirigir a si mesmo e descobrir sozinho sua própria normatividade sem um ser que o dirija: o autodidata é necessariamente adulto. Uma sociedade de autodidatas não pode aceitar a tutela e a menoridade espiritual. Ela aspira conduzir a si própria, a gestar a si mesma. Neste sentido principalmente e por seu poder tecnológico, que a Enciclopédia guardava consigo uma nova força e uma nova dinâmica social. A circularidade causal do conhecimento enciclopédico exclui a heteronomia moral e política da sociedade do Antigo Regime. O mundo técnico descobre sua independência quando ele realiza sua unidade; a Enciclopédia é uma espécie de Festa da Federação das técnicas que, pela primeira vez, descobrem a sua solidariedade.

\section{Natureza comum das técnicas menores e das técnicas maiores. Significação}

\section{do enciclopedismo}

Vamos tentar analisar a relação do espírito enciclopédico com o objeto técnico, porque ele parece ser um dos polos de toda consciência tecnológica e assim possuir, além de um significado histórico, um significado que é sempre valioso para o conhecimento da tecnicidade. Nós nos opusemos ao caráter implícito, instintivo e mágico da educação técnica dirigindo-se à criança segundo os caracteres inversos destes últimos, que se descobre na Enciclopédia; mas esta oposição corre o risco de mascarar uma profunda analogia dos dinamismos existentes nestas estruturas do conhecimento técnico; o enciclopedismo manifesta

\begin{tabular}{|l|l|l|l|l|}
\hline Q Rovista Qialectus & Ano 9 & n. 19 & Agosto - Dezembro 2020 & p. 322 - 347 \\
\hline
\end{tabular}


e propaga uma certa inversão dos dinamismos fundamentais da técnica; contudo, esse inversão só é possível porque as operações não estão apenas desvanecidas, mas deslocadas, de alguma forma invertidas. A Enciclopédia também manipula e transfere forças e potências; também realiza um feitiço e desenha um círculo como o círculo mágico, só que não enfeitiça da mesma maneira que a da prova no saber instintivo, e não é a mesma realidade que coloca dentro do círculo do saber. É a sociedade humana com suas forças e seus poderes obscuros o que está posto dentro do círculo, tornado imenso e capaz de cobrir tudo. O círculo é a realidade objetiva do [95] livro, que o representa e o constitui. Tudo o que é figurado no livro enciclopédico está em poder do indivíduo que possui, em seus detalhes mais secretos, um símbolo figurativo de todas as atividades humanas. A Enciclopédia realiza uma universalidade da iniciação, e através disso produz uma espécie de estilhaçamento do próprio sentido da iniciação; o segredo do universal objetivado conserva a noção de segredo no sentido positivo (perfeição de conhecimento, familiaridade com o sagrado), mas suprime o caráter negativo (escuridão, meio de exclusão através do mistério, conhecimento reservado a um pequeno número de homens). A técnica torna-se mistério esotérico ${ }^{4}$. A Enciclopédia é um encanto, tanto mais eficaz quanto a construímos com uma representação mais precisa, mais exata e mais objetiva que seu modelo; todas as competências ativas, todas as forças vivas das operações humanas estão reunidas neste objeto-símbolo. Cada indivíduo capaz de ler e compreender possui o encanto do mundo e da sociedade. Magicamente, cada um é mestre de tudo porque possui o encantamento de tudo. $\mathrm{O}$ cosmos, outrora envolvente e superior ao indivíduo, o círculo social limitativo e sempre descentrado em relação ao poder individual, estão agora nas mãos do indivíduo, como aquele globo representando o mundo, que os imperadores carregavam como sinal de soberania. $\mathrm{O}$ potência, a segurança do leitor da Enciclopédia é a mesma que a do homem que primeiro atacava um animal em efígie antes de abordá-lo na natureza, a mesma que a do agricultor primitivo que confiava a semente ao solo depois de ter realizado ritos propiciatórios, ou do viajante que não se aventurava em uma nova terra senão depois de ter, de alguma forma, a tornado favorável por meio de um ato estabelecendo uma comunhão e uma pré-possessão, de que a Odissei $\mathrm{a}^{5}$ nos conserva a lembrança. O gesto de iniciação é uma união com uma realidade

\footnotetext{
${ }^{4}$ Uma parte do sentimento de eficácia da magia primitiva transformou-se em crença incondicional no progresso. O objeto moderno ou o andamento moderno está coberto de um poder de eficácia quase que sobrenatural. $\mathrm{O}$ sentimento do moderno contém uma espécie de crença no poder ilimitado e polivalente de um objeto privilegiado.
}

\begin{tabular}{|c|c|c|c|c|}
\hline Qevista Dialectus & Ano 9 & n. 19 & Agosto - Dezembro 2020 & p. $322-347$ \\
\hline
\end{tabular}


que permanece hostil desde que não tenha sido dominada e possuída. É por esta razão que toda iniciação viriliza e torna adulta.

Toda manifestação do espírito enciclopédico pode então aparecer, segundo uma visão da psicossociologia, como um movimento [96] de fundo que expressa, em uma sociedade, a necessidade de chegar a um estado adulto e livre, porque o regime ou os hábitos de pensamento mantém em tutela e em estado de menoridade artificial os indivíduos; esta vontade de passar de uma menoridade para uma maioridade, ampliando o círculo de conhecimento e liberando o poder de conhecer, a encontramos em três passagens na história do pensamento desde a Idade Média. A primeira manifestação do espírito enciclopédico constitui a Renascença e é contemporânea da revolução ética e religiosa que é a Reforma. Querer passar do Vulgata para o verdadeiro texto da Bíblia, procurar os textos gregos em vez de se contentar com as pobres traduções latinas, reencontrar Platão para além da tradição escolástica cristalizada segundo um dogma fixo, é negar a limitação arbitrária do pensamento e do saber. A erudição não representa um retorno ao passado enquanto passado, mas a vontade de expandir o círculo do saber, de reencontrar todo o pensamento humano, a fim de ser liberto de uma limitação do saber.

O humanismo da Renascença não é, de maneira alguma, uma vontade de reencontrar uma imagem fixa do homem, a fim de restringir e de normalizar o saber, como o declínio de estudos antigos parecia fazê-lo acreditar nos nossos dias. O humanismo responde primeiro a um impulso enciclopédico. Mas esse impulso voltou-se para o saber já formalizado porque o nível de desenvolvimento das técnicas não era alto o suficiente para que uma formalização rápida deste domínio pudesse intervir; as ciências, sobretudo, eram muito pouco desenvolvidas; os meios intelectuais da universalização das técnicas não estavam prontos; foi o século XVII que forneceu os meios de universalização das técnicas, que a Enciclopédia colocou em prática; contudo, devemos salientar que desde a Renascença manifesta-se uma enorme acolhida das técnicas; já são valorizadas como paradigmas e meios de expressão ${ }^{6}$, pelo seu valor humano que abre novos caminhos. O magnífico elogio que faz Rabelais do Pantagruélião resume toda a esperança dos homens da Renascença, toda a sua crença na

${ }^{6} \mathrm{Na}$ Defesa e ilustração da língua francesa. Rabelais e Montaigne também usam muitos termos retirados dos ofícios.

\begin{tabular}{|c|c|c|c|c|}
\hline Qovista Dialectus & Ano 9 & n. 19 & Agosto - Dezembro 2020 & p. $322-347$ \\
\hline
\end{tabular}


"virtude" das técnicas graças às quais a humanidade poderá, talvez, ir um dia "até os sinais celestes", como ela soube ir do Velho para o Novo Mundo.

O segundo estágio enciclopédico é o das luzes; o pensamento científico estava liberto, mas o pensamento técnico não estava [97] livre; foi o pensamento científico que libertou o pensamento técnico. Como a técnica está ligada ao comércio, à agricultura, à indústria e como estes são aspectos da sociedade, este enciclopedismo tecnológico não poderia deixar de ser correlativo às reformas sociais e administrativas. As instituições tais como as Grandes Escolas saem do espírito enciclopédico; o enciclopedismo é, por definição, politécnico sob sua vertente industrial, como é fisiocrático por seu aspecto agrícola. $\mathrm{O}$ aspecto industrial desenvolveu-se mais do que o aspecto fisiocrático, porque a racionalização enciclopédica permitia transformações mais sensíveis no domínio industrial, que se beneficiava das recentes descobertas científicas do final do fim do século XVIII. No entanto, este desenvolvimento assimétrico não deve nos fazer esquecer de um dos componentes mais importantes do espírito enciclopédico técnico, a saber, a ligação direta do indivíduo com o mundo vegetal e animal, com a natureza biológica; ao invés de ser deixada para os descendentes dos antigos servos, a técnica de "arte do arado " é valorizada até pelas pessoas mais distintas. Esta época das "fazendas", e o tempo em que um espírito tão sólido quanto o de Daubenton não se recusa a escrever um tratado para uso dos pastores, que é o protótipo do livro de divulgação elevada e generosa, que retoma a antiga tradição das obras didáticas comunicando-lhe uma nova vida pelo uso de um simbolismo gráfico claro e compreensivo até para os iletrados; o essencial deste belo livro está nas gravuras, tão claras e expressivas como as da Enciclopédia. Devemos salientar, com efeito, que a tecnologia requer um outro meio de expressão que a expressão oral, que utiliza conceitos já conhecidos, e que pode transmitir emoções, mas dificilmente pode expressar esquemas de movimento ou estruturas materiais precisas; o simbolismo apropriado para a operação técnica é o simbolismo visual, com seu rico jogo de formas e proporções. A civilização da palavra dá lugar para a civilização da imagem. Ora, a civilização da palavra é, por sua própria natureza, mais restrita que a da imagem, porque a imagem é por natureza universal, não precisa de um código prévio de significações. Toda expressão verbal tende a se tornar iniciática; especializa-se sustentando-se numa espécie de linguagem cifrada, cujos velhos jargões corporativos são um exemplo claro. É preciso fazer parte de um grupo fechado para entender a

\begin{tabular}{|c|c|c|c|c|}
\hline Rovista Dialectus & Ano 9 & ก. 19 & Agosto - Dezembro 2020 & p. $322-347$ \\
\hline
\end{tabular}


linguagem oral ou escrita; [no caso da imagem] $]^{7}$ basta perceber para compreender a expressão esquemática. É com o esquema que o enciclopedismo técnico adquire todo o seu significado e poder de [98] difusão, tornando-se verdadeiramente universal. A impressão tinha dado nascimento a um primeiro enciclopedismo difundindo os textos; mas este enciclopedismo só poderia atender às significações reflexivas ou emotivas já sancionados pela cultura constituída; ao passar pela palavra, a informação que vai de indivíduo para indivíduo realiza um desvio pela instituição social que é a linguagem. O escrito impresso, por intermédio do signo visual, veicula inicialmente uma mensagem oral, com todas as limitações inerentes a este modo de expressão; a posse de todas as línguas vivas e todas as línguas antigas é necessária para o entendimento de um enciclopedismo de significações verbais; essa posse, ou pelo menos o esforço em direção a essa posse, faz parte do sentido da Renascença, mas permanece de fato o apanágio dos humanistas e acadêmicos; a cultura, através da linguagem oral ou escrita, não detém universalidade direta. É por esta razão, talvez, o motivo pelo qual a Renascença não pode constituir uma universalidade tecnológica, apesar de sua tendência a preferir, nas artes em particular, a expressão plástica e gráfica a qualquer outro simbolismo. A impressão, capacidade de difusão do esquema espacial, encontra seu pleno sentido na gravura. Ora, a gravura simbólica, usada como meio para traduzir claramente o pensamento das estruturas e das operações, libertada de toda vontade de expressão alegórica retornando a uma expressão oral (como os brasões falantes), aparece em seu desenvolvimento pleno no século XVII, nos tratados de Descartes, por exemplo. Tendo tomado sua força expressiva e seu poder de precisão do uso da geometria, está pronta para constituir o simbolismo apropriado de uma tecnologia universal.

Enfim, uma terceira etapa do pensamento enciclopédico parece anunciar-se à nossa época, mas ainda não alcançou sucesso na constituição de seus modos de expressão universal. A civilização do simbolismo oral venceu novamente a do simbolismo espacial, visual, porque os novos meios de difusão da informação têm dado primazia à expressão oral. Quando a informação tiver que ser convertida em um objeto impresso e transportado, o atraso que separa o pensamento descoberto do pensamento expresso é o mesmo para informação escrita e para a informação figurada. A impressão, privilegia, até melhor, a informação figurada, porque usa necessariamente a forma espacial; é o esquema que não tem a necessidade de ser traduzido de uma outra forma, que não seja a sua forma original, enquanto que a escrita representa a tradução

\begin{tabular}{|c|c|c|c|c|}
\hline Revista Dialectus & Ano 9 & n. 19 & Agosto - Dezembro 2020 & p. $322-347$ \\
\hline
\end{tabular}


em série espacial de uma série, temporal em sua [99] origem, que deverá ser reconvertida em leitura. Pelo contrário, na informação transmitida através da telefonia, telegrafia ou radiodifusão hertziana, o meio de transmissão requer a tradução de um esquema espacial em série temporal, reconvertida em seguida em um esquema espacial; a radiodifusão, em particular, está diretamente adaptada à expressão oral, e não pode ser adaptada, senão muito dificilmente, à transmissão de um esquema espacial; ela consagra primazia ao som. A informação espacial é então rejeitada no domínio de coisas caras ou raras, e sempre em atraso com relação à informação oral, que é valorizada porque segue passo a passo o devir vital ${ }^{8}$. Ora, uma civilização é guiada por um paradigma latente, no nível da valorização de sua informação; esse paradigmatismo torna-se novamente oral; o pensamento se desdobra novamente segundo semantemas verbais, da ordem do slogan. A presença ativa das relações inter-humanas é da ordem do verbo. Existem, certamente, o cinema e a televisão. Mas devemos salientar que a cinematografia, pela própria razão do dinamismo das imagens, é uma ação cinemática, dramática, mais do que um grafia do simultâneo, e não diretamente uma expressão da forma inteligível e estável; posteriormente em sua descoberta dos primeiros testes de transmissão de imagens pela televisão, suplantou totalmente esta última e lhe impôs o dinamismo das imagens, que sobrecarrega hoje a televisão com uma enorme carga e faz dela uma concorrente e uma imitadora da cinematografia, incapaz de descobrir seus próprios modos de expressão, subjugada ao público como meio de satisfação. O movimento cinematográfico é rico de uma hipnose e de um ritmo que entorpecem as faculdades reflexivas do indivíduo, para levá-lo a um estado de participação estética. Organizado de acordo com uma série temporal que emprega termos visuais, o cinema é uma arte e um meio de expressão das emoções; a imagem, neste caso, uma palavra ou uma frase, não é, aí, objeto que contém uma estrutura a ser analisada pela atividade do ser individual; ela, então, raramente se torna um símbolo imóvel e radiante. De outra forma, a televisão pode se tornar um meio de informação contemporâneo da atividade humana, o que o cinema não pode ser, porque sendo uma coisa fixa e gravada, coloca no passado tudo o que incorpora. Mas, como a televisão quer ser dinâmica, ela está obrigada a transformar em série temporal todos os pontos de cada imagem, e isto em um tempo muito curto como o da [100] projeção de cada imagem estática do cinema. Ela transforma então inicialmente o dinâmico em estático, graças a um primeiro corte nas imagens. Desta forma, durante a transmissão de cada

\begin{tabular}{|c|c|c|c|c|}
\hline${ }^{8}$ Ou social. & & & & \\
\hline Qovista Dialoctus & Ano 9 & n. 19 & Agosto - Dezembro 2020 & p. $322-347$ \\
\hline
\end{tabular}


imagem fixa, ela transforma em uma série temporal os pontos simultâneos desta imagem fixa; na chegada, cada série temporal se transforma em um quadro espacial imóvel, e a rápida sucessão dessas imagens fixas recria, como na cinematografia, o movimento analisado, por consequência as características da percepção do movimento. Esta dupla transformação cumprese pela necessidade de transmitir uma enorme quantidade de informação, mesmo para uma imagem extremamente simples em sua estrutura inteligível. Não há aqui nenhuma medida comum entre a quantidade de informação efetivamente interessante e significativa para o sujeito, e a quantidade de informação tecnicamente empregada, o que corresponde a vários milhões de sinais por segundo. Este desperdício de informação impede que a televisão dê ao indivíduo um meio flexível e fiel de expressão, e impede um verdadeiro simbolismo visual de se constituir universalmente; a radiodifusão cruza as fronteiras, enquanto a informação visual permanece frequentemente ligada à vida comunitária dos grupos; nessas condições ela não pode ser valorizada. Mas as pesquisas sobre os sistemas de codificação, úteis para inscrever sob uma tela de osciloscópio catódico os resultados das operações à calcular, ou para figurar sob o mesmo tipo de tela os sinais de detecção eletromagnética ${ }^{9}$, parece ter chegado a uma enorme simplificação para a transmissão de imagens esquemáticas por via hertziana; então a informação visual reencontrará, em relação à informação falada, o lugar que a radiodifusão a fez perder e seria capaz de fazer nascer um novo simbolismo universal.

Ora, a intenção enciclopédica começa a se manifestar nas ciências e nas técnicas, através da tendência para racionalizar a máquina e através da instituição de um simbolismo comum à máquina e ao homem; graças a esse simbolismo, é possível a sinergia entre homem e máquina; pois uma ação comum exige um meio de comunicação. E como o homem não pode ter vários tipos de pensamento (qualquer tradução corresponde a uma perda de informação), é sobre esta mistura da relação entre homem e máquina que um novo simbolismo universal [101] deve vir a se decalcar para ser homogêneo a um enciclopedismo universal.

O pensamento cibernético já oferece, na teoria da informação, pesquisas como a "human engineering", que estuda particularmente a relação entre homem e máquina; podemos conceber então um enciclopedismo em base tecnológica.

9 Em particular, no R.A.D.A.R Radio detection and Ranging (Localização e medida da distância por ondas hertzianas).

\begin{tabular}{|l|l|l|l|l|}
\hline Govista Dialectus & Ano 9 & n. 19 & Agosto - Dezembro 2020 & p. 322 - 347 \\
\hline
\end{tabular}


Este novo enciclopedismo, como os dois precedentes, deve efetuar uma liberação, mas num sentido diferente; ela não pode ser uma repetição com a do século das luzes. No século XVI, o homem se submetia aos estereótipos intelectuais; no século XVIII, estava limitado pelos aspectos hierárquicos da rigidez social; no século XX, é escravo de sua dependência em relação aos poderes desconhecidos e distantes que o dirigem sem que os conheça e possa reagir contra eles; é o isolamento que o escraviza, e a falta de homogeneidade da informação que o aliena. Tornando-se máquina em um mundo mecanizado, ele não pode voltar a encontrar sua liberdade, senão assumindo seu papel e superando-o através de uma compreensão das funções técnicas pensadas sob o aspecto da universalidade ${ }^{10}$. Todo enciclopedismo é um humanismo, se entendemos por humanismo a vontade de trazer de volta a um estatuto de liberdade o que foi alienado do ser humano, de modo que nada do humano seja estranho ao homem; mas esta redescoberta da realidade humana pode se efetuar em diferentes sentidos, e cada época recria um humanismo que é sempre, até certo ponto, o apropriado às circunstâncias, porque aponta para o aspecto mais grave da alienação que comporta ou produz uma civilização.

A Renascença definiu um humanismo apto para compensar a alienação devida ao dogmatismo ético e intelectual; ela visou reencontrar a liberdade do pensamento teórico intelectual; o século XVIII quis reencontrar a significação do esforço do pensamento humano aplicado às técnicas, e encontrou novamente, com a ideia de progresso, a nobreza dessa continuidade criativa que se descobre nas invenções; ele definiu o direito de existir da iniciativa técnica, apesar das forças inibidoras das sociedades. O século XX busca um humanismo capaz de compensar esta forma de alienação que intervém no próprio interior do desenvolvimento das técnicas, como consequência do que a sociedade exige e produz. Parece haver uma lei singular do devir do [102] pensamento humano, segundo a qual toda invenção, ética, técnica, científica, que é de início um meio de liberação e redescoberta do homem, converte-se, por evolução histórica, em um instrumento que se volta contra o seu próprio fim e escraviza o homem, limitando-o: o cristianismo foi em sua origem uma força libertadora, que convocou o homem para além do formalismo dos costumes e dos prestígios institucionais da sociedade antiga.

\footnotetext{
$10 \mathrm{O}$ homem atual tem uma forte inclinação que o empurra a se comportar como uma máquina portadora de ferramentas, porque cumpriu essa função por muitos séculos antes da criação das máquinas, em um momento em que havia elementos técnicos, sob a forma de ferramentas e conjuntos técnicos, sob a forma de oficinas e estaleiros, mas não indivíduos técnicos, na forma de máquinas.
}

\begin{tabular}{|l|l|l|l|l|}
\hline Qenista Dialectus & Ano 9 & n. 19 & Agosto - Dezembro 2020 & p. 322 - 347 \\
\hline
\end{tabular}


Era o pensamento segundo o qual o Sabbat é feito para o homem, e não o homem para o Sabbat; entretanto, esse mesmo cristianismo que os reformadores da Renascença acusam de se constituir uma força rígida ligada ao formalismo e ao dogmatismo coercivo, contrário ao sentido real e profundo da vida humana. A Renascença opôs a physis à antiphysis. Da mesma forma, as técnicas, invocadas como libertadoras através do progresso, no século das luzes, são acusadas de subjugar o homem, e de o reduzir à escravidão desnaturando-o, tornando-o estranho a ele mesmo através da especialização, que é uma barreira e uma fonte de incompreensão. $\mathrm{O}$ centro de convergência tornou-se princípio de compartimentação. Por este motivo, o humanismo não pode ser nunca uma doutrina nem mesmo uma atitude que poderia se definir uma vez por todas; cada época deve descobrir seu humanismo, orientando-o para o principal perigo da alienação. Na Renascença, o fechamento do dogma gerou a eclosão de um novo fervor e de um novo impulso.

No século XVIII, a fragmentação infinita da hierarquia social e das comunidades fechadas levou à descoberta de um meio de eficácia universal e não mediada, pela racionalização e a universalização do gesto técnico, ultrapassando todas as barreiras e proibições que os hábitos haviam instituído. No século XX, não é mais a fragmentação hierárquica ou local da sociedade que cria a alienação da sociedade humana em relação ao homem, mas antes sua imensidão vertiginosa, sem limite, em movimento; o mundo humano da ação técnica tornou-se estranho ao indivíduo ao desenvolver-se e ao formalizar-se, ao endurecer-se também sob a forma de um maquinismo, que se torna um novo acessório do indivíduo no mundo industrial, que ultrapassa a dimensão e a possibilidade de pensar do indivíduo. A técnica libertadora [103] do século XVIII é a dimensão do indivíduo, porque ela é do tipo artesanal. Aquela do século XX encontra-se para além das forças do indivíduo e constitui no mundo industrial uma realidade humana compacta e resistente, mas alienada, e também completamente fora do alcance do indivíduo como o foi anteriormente uma sociedade hierarquizada ${ }^{11}$.

\footnotetext{
${ }^{11}$ Durante os séculos passados, uma importante causa de alienação residia no fato de que que o ser humano emprestou sua individualidade biológica à organização técnica: era um portador de ferramentas; os conjuntos técnicos só poderiam se constituir incorporando o homem como portador de ferramentas. $\mathrm{O}$ caráter deformante da profissão era, ao mesmo tempo, psíquico e somático. O portador de ferramentas era deformado pelo uso de das ferramentas. As deformações somáticas profissionais tornaram-se raras em nossos dias. Na repugnância que experiencia todo homem honrado com relação às funções de ofício, entra, possivelmente, uma parte do sentimento desagradável que nós experimentamos quando se contempla uma monstruosidade. Os maus profissionais da

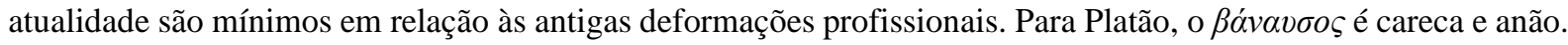
Em uma lenda cantada, o pequeno sapateiro é um ser deserdado.
}

\begin{tabular}{|c|c|c|c|c|}
\hline Rovista Dialectus & Ano 9 & n. 19 & Agosto - Dezembro 2020 & p. $322-347$ \\
\hline
\end{tabular}


O homem já não precisa mais de uma liberação universalizante, mas de uma mediação. A nova magia não estará mais por ser descoberta na irradiação direta do poder individual de agir, assegurada pelo saber que oferece ao gesto a certeza eficaz, mas na racionalização daquelas forças que situam o homem oferecendo-lhe uma significação no conjunto humano e natural. O simples fato de tratar a teleologia como um mecanismo conhecível e não definitivamente misterioso mostra a tentativa de não aceitar uma situação simplesmente sofrida e vivenciada. No lugar de procurar o procedimento para fabricar objetos sem fazer um pacto com a matéria, o homem liberta-se da situação de ser colocado em condição de servidão pela finalidade do todo aprendendo a construir a finalidade, a organizar um todo finalizado que ele julgue e aprecie, de modo a não ter que padecer passivamente uma integração de fato. A Cibernética, teoria da informação e, por consequência também, teoria das estruturas e dos dinamismos finalizados, libera o homem do fechamento restritivo da organização, tornando-o capaz de julgar esta organização, em vez de sofrer venerando-a e respeitando-a, porque não é capaz de pensá-la ou de constituí-la. O homem supera a escravidão organizando conscientemente a finalidade, como dominou durante o século XVIII, a necessidade desditosa do trabalho racionalizando-o, para fazer um trabalho eficaz, ao invés de sofrer com resignação. A sociedade humana conhecendo seus próprios mecanismos teleológicos, resultado do pensamento humano consciente, incorpora por consequência aqueles que o fazem; ela é um produto do esforço humano organizador e cria a adequação entre o fato de estar situada e o fato de se situar. O lugar do homem na sociedade torna-se então a relação entre um elemento ativo e um elemento de passividade, como um estatuto misto suscetível de sempre de ser retomado e aperfeiçoado, porque ele é do humano interrompido, mas não alienado. A consciência [104] é por sua vez atividade demiúrgica e resultado de uma organização anterior; a realidade social é contemporânea do esforço humano e homogênea em relação a ele. Apenas um esquema de simultaneidade, uma constelação de forças representadas em seu poder relacional, pode ser apropriada para este tipo de realidade. É o seu desenvolvimento que postula uma tal representação dinâmica do homem na sociedade; os esquemas cibernéticos não podem encontrar um sentido universal, senão em uma sociedade já constituída de acordo com esse pensamento; a reatividade mais difícil a se estabelecer é a da sociedade em relação ao pensamento cibernético em si mesmo; ele só pode ser criado progressivamente e através da

\begin{tabular}{|l|l|l|l|l|}
\hline Gevista Qialectus & Ano 9 & n. 19 & Agosto - Dezembro 2020 & p. 322 - 347 \\
\hline
\end{tabular}


intermediação de canais de informação já constituídos, como por exemplo as trocas entre técnicas trabalhando de maneira sinérgica em um determinado ponto; é este tipo de agrupamento que Norbert Wiener cita como uma fonte desta nova tecnologia que é uma técnica das técnicas, no início de sua obra intitulada Cibernética, publicado em 1948, e que é um novo Discurso do Método, elaborado por um matemático que leciona em um instituto de tecnologia. A Cibernética dá ao homem um novo tipo de maioridade, a que penetra nas relações de autoridade distribuindo-se no corpo social, e que descobre, para além da maturidade da razão, a da reflexão que oferece, bem mais que a liberdade de agir, o poder de criar a organização de modo a instituir a teleologia. Da mesma forma, a finalidade e a organização, podendo ser racionalmente pensadas e criadas, uma vez que elas se convertem em conteúdo das técnicas, elas já não são mais razões últimas, superiores, capazes de tudo justificar: se a finalidade tornase objeto da técnica, existe para além da finalidade na ética; a cibernética, nesse sentido, libera o homem do prestígio incondicional da ideia de finalidade. O homem libera-se, através da técnica, da coerção social; pela tecnologia de informação, ele se torna o criador dessa organização de solidariedade que anteriormente o aprisionava; a etapa do enciclopedismo técnico não pode ser senão temporária; ela convoca a do enciclopedismo [105] tecnológico, que a completa oferecendo ao indivíduo a chance de voltar ao social que muda de estatuto, e se torna o objeto de uma construção organizadora em vez de ser a aceitação de um dado valorizado ou combatido, mas que subsiste com seus caracteres primitivos, externos à atividade do homem. A natureza individual não é mais, assim, externa ao domínio humano. Após o acesso à liberdade, manifesta-se o acesso à autoridade, no sentido pleno do termo, que é o da força criativa.

Estas são as três etapas do espírito enciclopédico, que foi, de início, ética, depois técnica, e que pode tornar-se tecnológica, indo para além da ideia de finalidade tomada como justificação última.

Ora, não é necessário dizer que as técnicas da organização finalizadas são úteis somente por seus resultados práticos; são úteis no sentido de que elas fazem passar a finalidade do nível mágico para o nível técnico. Então, que a evocação de um fim superior, e de ordem que realize este fim, é considerada como termo último de um requisito de justificação, porque a vida é confundida com a finalidade, em uma época em que os esquemas técnicos são apenas esquemas de causalidade, a introdução no pensamento de esquemas tecnológicos de finalidade

\begin{tabular}{|l|l|l|l|l|}
\hline Qevista Dialectus & Ano 9 & n. 19 & Agosto - Dezembro 2020 & p. 322 - 347 \\
\hline
\end{tabular}


joga um papel catártico. Onde há técnica não pode haver uma justificação última. A vida, individual e social, comporta, na verdade, aspectos de processos finalizados, mas a finalidade não pode ser o aspecto mais profundo da vida individual ou social, tão pouco as diferentes modalidades da ação finalizada, como a adaptação a um meio.

Sem dúvida, poderíamos dizer que não é uma verdadeira finalidade que anima os processos de causalidade recorrente à reação negativa; finalmente esta produção técnica de mecanismos teleológicos nos permite sair do domínio mágico, o aspecto mais inferior, o mais grosseiro da finalidade: a subordinação dos meios a um fim, logo a superioridade do fim em relação aos meios. Tornando-se matéria técnica, semelhante organização não é senão um dos aspectos da vida social ou individual, e não pode mais mascarar, com seu prestígio, as possibilidades de desenvolvimento, de advento, de surgimento de novas formas, que não podem ser justificadas pela finalidade, porque elas produzem seu próprio fim como termo último da evolução; a evolução desadapta tanto quanto adapta. A realização das adaptações não é mais que um dos aspectos da vida; as homeostases são funções parciais; a tecnologia, envolvendoos e permitindo não [106] somente pensá-los, mas também realizá-los racionalmente, deixa em plena luz processos abertos da vida social e individual. Nesse sentido, a tecnologia reduz a alienação.

IV. Necessidade de uma síntese no nível da educação entre o modo maior e o modo menor de acesso às técnicas

A separação entre a educação de adultos e a educação da criança no campo da tecnologia responde a uma diferença na estrutura dos dois sistemas normativos e, em parte, a uma diferença entre os resultados. A consequência é que até agora há um intervalo que não pode ser franqueado entre a tecnologia pedagógica e a tecnologia enciclopédica.

A educação enciclopédica tecnológica visa oferecer ao adulto o sentimento de que ele é um ser acabado, inteiramente realizado, em plena posse de seus meios e de suas forças, imagem do homem individual em seu estado de real maturidade; a condição necessária de tal sentimento é a universalidade do direito e de fato, do conhecimento; ora, há ainda algo de abstrato na formação enciclopédica, e uma imperfeição intransponível da universalidade: com efeito, a reunião material de todos os dispositivos técnicos em uma compilação tecnológica que os reúna coordenando-os de acordo com a ordem de simultaneidade, ou da razão, deixa de lado o caráter temporal, sucessivo, quântico das descobertas que conduziram ao estado atual; nos

\begin{tabular}{|l|l|l|l|l|}
\hline Q onista Dialectus & Ano 9 & n. 19 & Agosto - Dezembro 2020 & p. 322 - 347 \\
\hline
\end{tabular}


apoderamos imediatamente do atual que é construído progressivamente, lentamente e sucessivamente elaborado; a ideia de progresso, no que ela tem de mítico, vem dessa ilusão de simultaneidade, que nos faz tomar por situação o que não é mais do que uma etapa; o enciclopedismo, excluindo a historicidade, introduz o homem na posse de uma falsa enteléquia, pois esta etapa é ainda rica em virtualidades; nenhum determinismo preside a invenção, e se o progresso é pensado como contínuo, mascara a própria realidade da invenção. O autodidata é tentado a trazer tudo de volta para o presente, o passado enquanto o traz novamente em seu conhecimento presente, e o futuro enquanto o considera como devendo decorrer de maneira contínua do presente através do progresso. Falta ao autodidata ter sido elevado, isto é, de ter se tornado adulto de forma progressiva, através de uma série temporal de desenvolvimentos estruturados pelas crises que os delimitam e permitem a passagem [107] para outra fase; é necessário ter apreendido a historicidade do devir técnico através da historicidade do devir do sujeito para acrescentar à ordem do simultâneo a do sucessivo, segundo a forma que é o tempo. $\mathrm{O}$ verdadeiro enciclopedismo, exigindo universalidade temporal ao mesmo tempo que a universalidade do simultâneo, deve integrar a educação da criança; ele não pode tornar-se verdadeiramente universal senão forjando o adulto através da criança, seguindo a universalidade temporal para obter a universalidade do simultâneo; é necessário descobrir a continuidade entre as duas formas de universalidade.

Inversamente, a educação tecnológica carece da universalidade do simultâneo, o que exprimimos ao dizer que ela visa a cultura de preferência ao saber; mas uma iniciativa que desejasse obter a cultura livrando-se do conhecimento seria ilusória, porque a ordem enciclopédica do saber faz parte da cultura; ora, [o conhecimento] ${ }^{12}$ não pode mais ser apreendido senão de maneira abstrata e, consequentemente, não cultural, se ele é tomado fora do próprio saber. A representação do saber sem o próprio saber não pode se realizar senão pela tomada de um símbolo exterior, como por exemplo, por meio da representação mítica e socializada pelos homens que "encarnam" o saber: o saber é substituído pela figura do sábio, isto é, por um elemento de tipologia social, ou caracterológico catalogado, totalmente inadequado ao próprio saber, e que introduz no cultura uma mistificação que a faz inautêntica. Ou melhor, o saber pode ser substituído por uma opinião, uma biografia, um traço de caractere ou uma descrição do personagem de um sábio; mas estes são, ainda, elementos totalmente

12 Acréscimo dos tradutores.

\begin{tabular}{|l|l|l|l|l|}
\hline Q Povista Dialectus & Ano 9 & n. 19 & Agosto - Dezembro 2020 & p. 322 - 347 \\
\hline
\end{tabular}


inadequados, porque introduzem não o saber, mas a uma idolatria dos suportes humanos do saber, o que não é da ordem do próprio saber. Existe uma cultura mais autêntica no gesto de uma criança que reinventa um dispositivo técnico do que no texto onde Chateaubriand descreve este "gênio espantoso" que era Blaise Pascal. Estamos mais próximos da invenção quando tentamos compreender o dispositivo de somar por rodas em meia-esquadria, empregada na máquina de calcular de Pascal (máquina aritmética), apenas quando lemos as passagens mais eloquentes relacionadas ao gênio de Pascal. Compreender Pascal é refazer com as próprias mãos uma máquina igual à sua, sem copiá-la, transpondo-a mesmo, se possível, em dispositivo eletrônico de soma, para ter que voltar a inventar em vez de reproduzir, atualizando os esquemas intelectuais e operatórios que foram [108] os de Pascal. Cultivar-se é atualizar analogicamente os esquemas humanos reais, em ocupando-se apenas de maneira acessória das turbulências que tal invenção, tal publicação, tiveram para os contemporâneos, porque elas não são essenciais, ou pelo menos podem ser tomadas somente com referência ao pensamento original, à própria invenção.

Podemos lamentar que um estudante cultivado de uma última série do ensino médio conheça a teoria da turbulência de Descartes através dos melindres de Belize, e o estado da astronomia do século XVII por "aquela luneta longa que metia medo nas pessoas", que Chrysale não pode tolerar.

Há aqui falta de seriedade, uma falta de verdade no pensamento que não pode, de maneira alguma, ser apresentada como uma cultura. Estas evocações estariam no lugar se elas pudessem ser localizadas em relação à sua fonte real, captada anteriormente, e não através do farisaísmo de uma obra de arte que tem outros propósitos para além dos da cultura. A ordem enciclopédica do simultâneo encontra-se expulsa do ensino cultural porque situa-se em conformidade com opiniões dos grupos sociais, que não possuem uma representação da ordem do simultâneo, porque só representam uma mínima fração da vida em uma determinada época, e porque eles não podem circunscrever a si mesmos. Este hiato entre a vida atual e a cultura vem da alienação da cultura, isto é, do fato de que a cultura é na realidade uma iniciação às opiniões de grupos sociais determinados que existiram em épocas anteriores; o primado das letras na educação cultural vem dessa onipotência da opinião; uma obra, e em particular uma obra que sobreviveu, é de fato uma obra que expressou a ética de um grupo ou de uma época, de maneira tal que esse grupo se reconheça nela; uma cultura literária é então escrava dos

\begin{tabular}{|l|l|l|l|l|}
\hline Q onista Dialectus & Ano 9 & n. 19 & Agosto - Dezembro 2020 & p. 322 - 347 \\
\hline
\end{tabular}


grupos; está no nível dos grupos do passado. Uma obra literária é um testemunho social. Toda vertente das obras didáticas está removida da cultura, a menos que seja antiga, e possa ser considerada como um testemunho do "gênero" didático. A cultura atual finge considerar o gênero didático como extinto hoje em dia, enquanto que, talvez, jamais tenha tido tanta força expressiva, tanta arte, tanta presença humana como nos escritos científicos e técnicos. Na realidade, agora, a cultura se tornou um gênero com suas regras e suas normas fixas; ela perdeu seu senso de universalidade.

A educação, para ser inteiramente educativa, carece, portanto, de [109] dinamismos humanos. Se consideramos particularmente o aspecto técnico desta educação e deste enciclopedismo, vemos que constitui um mediador de grande valor, porque traz consigo aspectos pelos quais é acessível à criança e outros aspectos pelos quais simboliza adequadamente os sucessivos estados do saber científico; isso constitui, com efeito, o obstáculo contra o qual vem se quebrar a educação cultural quando ela quer se tornar enciclopédica; é a dificuldade de entender, a partir de símbolos intelectuais discursivos, aquela ciência que se gostaria de conhecer. Ao contrário, a realização técnica oferece o conhecimento científico que serve como princípio de funcionamento, sob a forma de intuição dinâmica apreensível até mesmo por uma criança pequena e suscetível de ser melhor elucidada, duplicada por uma compreensão discursiva; o verdadeiro conhecimento discursivo não admite graus; é de cara perfeito ou falso porque inadequado. O enciclopedismo poderia, assim, através das técnicas, encontrar o seu lugar na educação da criança, sem exigir as habilidades de abstração as quais a criança não pode dispor plenamente. Nesse sentido, a aquisição dos conhecimentos tecnológicos por parte da criança pode iniciar-se por um enciclopedismo intuitivo, apreendido através do caráter do objeto técnico. De fato, o objeto técnico se distingue do objeto científico porque este último é um objeto analítico, que visa analisar um efeito único com todas as suas condições e características mais precisas, enquanto que o objeto técnico, longe de estar completamente no contexto de uma ciência particular, encontra-se de fato no ponto de convergência de uma multidão de dados e de efeitos científicos provenientes dos domínios os mais variados, integrando os saberes aparentemente os mais heteróclitos, e que podem não estar intelectualmente coordenados, enquanto estão praticamente no funcionamento do objeto técnico; podemos dizer que o objeto técnico resulta de uma arte de compromisso; o que é, com efeito, uma estrutura eminentemente sintética, não podendo ser compreendida de outro modo

\begin{tabular}{|l|l|l|l|l|}
\hline Q Rovista Qialectus & Ano 9 & n. 19 & Agosto - Dezembro 2020 & p. 322 - 347 \\
\hline
\end{tabular}


senão pela introdução de um esquematismo sintético que preside a invenção. $O$ esquema técnico, relação entre várias estruturas e uma operação complexa que se cumpre através dessas estruturas é, por sua própria natureza enciclopédica, já que ele realiza uma circularidade de conhecimentos, uma sinergia dos elementos ainda teoricamente heterogêneos do saber.

Talvez poderíamos ressaltar que, até o século XX, as técnicas foram incapazes de assumir este papel da relação entre o trabalho enciclopédico e a cultura oferecida à criança. Com [110] efeito, neste momento, era ainda difícil encontrar, no seio das técnicas, operações verdadeiramente universais, incluindo os esquematismos da sensação ou do pensamento. Hoje, a existência de técnicas de informação oferece à tecnologia uma universalidade infinitamente maior. A teoria da informação coloca o tecnologia no centro de um grande número de ciências as mais diversas, como a fisiologia, a lógica, a estética, o estudo fonético ou gramatical e mesmo semântico das línguas, o cálculo numérico, a geometria, a teoria da organização dos grupos e dos regimes de autoridade, o cálculo de probabilidades, e todas as técnicas de transporte da informação falada, sonora ou visual. A teoria da informação é uma tecnologia intercientífica, que permite uma sistematização de conceitos científicos, bem como o esquematismo das várias técnicas; não devemos considerar a teoria da informação como uma técnica entre as técnicas; ela é, na realidade, um pensamento mediador entre as diversas técnicas, de uma parte, e entre as várias ciências, de outra parte, e finalmente entre as ciências e as técnicas; ela pode desempenhar esse papel porque existem relações entre ciências que não são apenas teóricas, mas também instrumentais, técnicas, cada ciência podendo tomar a seu serviço um certo número de outras ciências que utiliza como fontes técnicas para realizar o efeito que estuda; a relação técnica existe entre as ciências; de outra forma, as técnicas podem teorizar-se sob a forma de ciência; a teoria da informação intervém como ciência das técnicas e técnica das ciências, determinando um estado recíproco destas funções de troca.

Neste nível, e somente neste nível, que o enciclopedismo e a educação técnica podem se reencontrar, em uma coerência de duas ordens, simultânea e sucessiva, da universalidade.

Podemos dizer então que, se as técnicas até hoje não puderam conceder dois dinamismos dificilmente conciliáveis, um destinado ao adulto e o outro à criança, esse antagonismo deixa lugar, na teoria da informação, a uma disciplina mediadora, que estabelece a continuidade entre a especialização e o enciclopedismo, entre a educação da criança e a

\begin{tabular}{|l|l|l|l|l|}
\hline Qevista Dialectus & Ano 9 & n. 19 & Agosto - Dezembro 2020 & p. 322 - 347 \\
\hline
\end{tabular}


educação do adulto. Através disso, funda-se uma tecnologia reflexiva acima das diferentes técnicas, e define um pensamento que cria uma relação entre as ciências e as técnicas.

A consequência dessa unificação reflexiva das técnicas e do fim da oposição entre saber teórico e saber [111] prático é importante para a concepção reflexiva do homem; uma vez atingido este nível, com efeito, não há mais hiato ou antagonismo entre o tempo da educação e a idade adulta; a ordem do sucessivo e a ordem do simultâneo se organizam em relação recíproca, e o tempo do adulto não é mais antagônico em relação ao tempo da educação. Em certa medida, inclusive, a evolução das sociedades, suspensa até aqui por um determinismo da juventude, depois da maturidade e finalmente da velhice, com os regimes políticos e sociais correspondentes, não pode mais ser concebida como fatal se a penetração das técnicas é muito profunda para introduzir um sistema de referências e de valores independentes desse biologismo implícito.

Uma análise atenta dos dualismos em sistemas de valores, como o do manual e do intelectual, do camponês e do cidadão, da criança e do adulto, mostraria que, no fundo dessas oposições, há uma razão técnica de incompatibilidade entre os vários grupos de esquematismos; o manual é aquele que vive de acordo com um esquematismo intuitivo no nível das coisas materiais; pelo contrário, o intelectual é aquele que conceitualizou as qualidades sensíveis; vive de acordo com uma ordem que estabiliza a ordem do sucessivo em definições da natureza e do destino do homem; detém um certo poder de conceitualizar e valorizar ou desvalorizar os gestos humanos e os valores vividos no nível da intuição. O manual vive de acordo com a ordem do simultâneo; ele é autodidata quando quer acessar uma cultura. É segundo a mesma diferença entre os esquemáticos que o homem do campo se opõe ao homem da cidade. O homem do campo é contemporâneo de um conjunto de exigências e participações que fazem dele um ser integrado em um sistema natural de existência; suas tendências e intuições são os laços desta integração. O homem da cidade é um ser individual, ligado a um devir social mais que a uma ordem natural. Opõe-se ao homem do campo como um ser abstrato e cultivado, a um ser integrado e inculto. $\mathrm{O}$ homem da cidade é de um tempo, enquanto o do campo é de uma região; o primeiro integra-se à ordem do sucessivo, o segundo, na ordem do simultâneo. Em geral, observamos o apego do homem rural às tradições; mais precisamente a tradição é o aspecto mais inconsciente da historicidade, que mascara a representação da ordem do sucessivo, e que supõe uma invariância da sucessividade. $\mathrm{O}$ real tradicionalismo repousa na ausência de uma

\begin{tabular}{|l|l|l|l|l|}
\hline Qevista Dialectus & Ano 9 & n. 19 & Agosto - Dezembro 2020 & p. 322 - 347 \\
\hline
\end{tabular}


representação da série do devir; este devir desapareceu. Enfim, a oposição entre a criança e o adulto [112] resume esses antagonismos; a criança é o ser do sucessivo, feito de virtualidades, modificando-se no tempo e tendo consciência desta modificação e desta mudança. $\mathrm{O}$ adulto, que lhe apresenta a vida, integra-se à sociedade segundo a ordem da simultaneidade. Essa maturidade aliás não pode ser plenamente atendida senão na medida onde a sociedade é estável e não celeremente evolutiva, sem a qual uma sociedade em movimento de transformação, que privilegia a ordem do sucessivo, comunica a seus membros adultos um dinamismo que faz deles adolescentes.

\begin{tabular}{|l|l|l|l|l|}
\hline Qevista Dialectus & Ano 9 & n. 19 & Agosto - Dezembro 2020 & p. 322 - 347 \\
\hline
\end{tabular}

